\title{
Types of pain and their psychosocial impact in women with rheumatoid arthritis
}

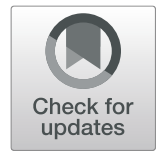

\author{
Maria Gabriela Chancay ${ }^{1 *}$, Shirin Nouri Guendsechadze ${ }^{2}$ and Irene Blanco ${ }^{1}$ (D)
}

\begin{abstract}
Rheumatoid arthritis (RA) is a systemic inflammatory autoimmune disease predominantly affecting middle-aged women. Very commonly, pain is a manifestation of active disease and because untreated RA can result in joint deformities, the current evaluation of pain has largely focused on inflammation. In addition, treatment has centered on the premise of reducing disease activity with the hopes of halting worsening damage, preventing future deformities, and ultimately providing pain relief for the patient. Yet research shows that all patients with RA, but women in particular, often suffer from increased mechanical pain and fibromyalgia, as well as anxiety, depression, sleep disturbances, sexual dysfunction, and disability, which add to the burden of the illness. Determining and addressing alternative pain triggers as well as understanding the psychosocial burden of RA is key in treating patients, especially in those who may not improve with traditional pharmacotherapy.
\end{abstract}

Keywords: Rheumatoid arthritis, Non-inflammatory pain, Women, Middle age

\section{Introduction}

Rheumatoid arthritis (RA) is a chronic, systemic, inflammatory disease, classically affecting the small joints of the hands and feet [1]. In industrialized countries, RA affects $0.5-1.0 \%$ of adults and there are approximately $5-50$ new cases per 100,000 adults per year [2]. Like most autoimmune diseases, RA primarily affects women with a female to male ratio of 3:1 $[2,3]$. Among men younger than 45 years of age, RA is rare while it occurs four times more often in women who are less than 50 years old [3-5]. With age, the incidence of RA among men increases but so does the incidence of RA among women, which peaks around menopause [3-5]. While the disease can occur in either sex at any age, it is predominately a disease of middle-aged women. Like men with RA, these women are at increased risk for cardiovascular events and are at increased risk for total mortality [6].

The discrepancy in the incidence and prevalence of RA among the sexes suggests that there are factors associated with the female sex that play a role in the development and progression of RA, with the literature focusing primarily on a hormonal component. Studies

\footnotetext{
* Correspondence: maria.g.chancay@gmail.com

${ }^{1}$ Department of Rheumatology, Albert Einstein College of Medicine, 1300

Morris Park Ave, Forchh 701N, Bronx, NY 10461, USA

Full list of author information is available at the end of the article
}

on hormonal differences, however, have yielded conflicting results. Pregnancy and breastfeeding, for example, have been associated with a decreased risk of developing RA $[4,7,8]$. Concomitantly, the post-partum and postmenopausal periods, and in particular, early-onset menopause (less than 44 years old) have been associated with an increased risk $[4,7,9]$. This would suggest a protective role of estrogen in RA, yet this is inconsistent with the fact that the disease is more common in women versus men and that studies of hormone replacement therapy and oral contraceptives have shown inconsistent results $[8,10,11]$.

A critical issue in the management of RA is recognition that not all pain in RA is due to active disease. Patients with RA also experience non-inflammatory pain which includes mechanical pain (like osteoarthritis), neuropathic pain, fibromyalgia, side effects of treatment, as well as the psychosocial sequela from the disease like depression, anxiety, sleep disturbances, sexual dysfunction, and disability $[1,6,12,13]$. Given the available literature, this review will focus on how women are affected by these non-inflammatory pain generators. Secondly, it seeks to encourage clinicians and researchers to take a broader approach to pain when working with patients with RA.

Currently the focus in RA treatment is to decrease inflammation and achieve remission in an effort to

(c) The Author(s). 2019 Open Access This article is distributed under the terms of the Creative Commons Attribution 4.0 International License (http://creativecommons.org/licenses/by/4.0/), which permits unrestricted use, distribution, and 
prevent deformities and erosions. While this should certainly be a goal in treatment, a reduction of inflammatory pain may not be enough to address the myriad of ways RA drastically affects patient's lives. Failing to recognize that inflammation is not the only cause of pain in RA can lead to unnecessary changes in therapy and a lack of attention to non-inflammatory targets of pain management and psychosocial support [14].

\section{Pathophysiology of rheumatoid arthritis}

\section{A. Mechanism}

The pathophysiology of RA is complex, multifactorial, and is not yet fully understood. The current hypothesis is that in genetically susceptible individuals, environmental factors can trigger an aberrant activation of the immune system, including excess production of tumor necrosis factor-alpha (TNF-alpha) and interleukin-1 (IL-1), leading to the clinical onset of disease [4, 12]. In RA, approximately two-thirds of the risk of developing the condition is attributed to genetic factorsmainly the HLA-DRB1 alleles which encode a fiveamino acid sequence motif known as the shared epitope (SE) $[15,16]$. It remains unclear how exactly the shared epitope interacts with environmental factors and leads to the RA inflammatory cascade, although viral infections, commensal bacteria, and cigarette smoke among others have been implicated [15]. It has been suggested that in patients with the SE, cigarette smoke may activate protein citrullination in the lungs, which can become antigenic and form anti-citrullinated protein antibodies (ACPA). These proteins contribute to the dysregulation of the immune system [15].

\section{B. Clinical presentation}

Although a multi-systemic problem, RA classically presents as a chronic inflammatory disease of synovial joints. It typically manifests as polyarticular pain with a symmetric distribution mainly affecting the hands and the feet. In the hands, it has a preference for the wrists, as well as the metacarpophalangeal and proximal interphalangeal joints. These joints are not only painful but also often swollen and warm. Morning stiffness lasting for more than $30 \mathrm{~min}$ is typically present. Rheumatoid factor (RF) and ACPA are often seen in addition to elevated acute phase reactants, i.e. sedimentation rate and creactive protein. About 50 to $80 \%$ of RA patients have RF, ACPA, or both and the presence of these antibodies are associated with worsened prognosis [2]. Untreated, RA can lead to joint deformities with irreversible bone and cartilage destruction leading to disability and a decreased quality of life [12]. Extraarticular manifestations can occur, especially in those that are untreated, examples are: rheumatoid nodules, interstitial lung disease, vasculitis, mononeuritis multiplex, and scleritis [2]. RA can also be seen in association with other conditions such as Felty's syndrome(RA, splenomegaly, and neutropenia) and Caplan's syndrome(RA and pneumoconiosis). In some cases, RA can exist in conjunction with other autoimmune diseases including Sjögren's syndrome and systemic lupus erythematosus [17].

Despite the extra-articular manifestations that RA can have, it most commonly presents with joint pain and morning stiffness. RA activity is evaluated by using composite measures like the clinical disease activity index (CDAI) or the simplified disease activity index (SDAI), which are composed of the number of swollen joints, tender joints, the patient global assessment, and the clinician global assessment, with the SDAI also including the c-reactive protein. These disease indices include both objective and subjective measures (the number of tender joints and patient global assessment) and traditionally have assumed that all factors are primarily driven by the inflammatory component of RA.

Several studies have shown that elevated composite measures that include patient-reported components can also reflect the presence of non-inflammatory pain [14]. A cross-sectional study in Italy of 292 patients with RA showed that patients with comorbid fibromyalgia compared to patients with RA only, had higher tender joint counts and DAS 28 score (another disease activity score similar to CDAI or SDAI) despite having similar disease activity as measured by rates of erythrocyte sedimentation rate and swollen joint counts [18]. In Sweden, a separate cross-sectional study found that one-third of 102 women with early RA also met criteria for widespread pain. The women with widespread pain reported a higher number of tender joints, greater pain intensity, worse global health, activity limitation, fatigue, depression, and anxiety. This is despite inflammation being similar between the groups [13]. This and other studies looking at sleep, neuropathic pain, and emotional health suggest that there is a relationship between RA and non-inflammatory pain generators. The latter seems to contribute to the intensity of pain and also add to psychosocial stress, which in turn can also act as a non-inflammatory pain trigger and affect the way RA is experienced [2,13,14,19-22]. In one study, for example, women with RA and widespread pain were found to have reduced hand-grip force and muscle endurance, compared to women with RA only, despite the fact that disease activity was similar. The study then suggests that these women are at a higher risk for activity limitation in the future as a result of their decreased force and endurance [13]. 
Non-inflammatory pain generators in rheumatoid arthritis

\section{A. Mechanical pain}

While active RA can cause inflammatory pain, discomfort can continue even after inflammation has subsided. Bone and cartilage destruction can lead to the development of secondary osteoarthritis resulting in mechanical pain despite disease remission or low disease activity $[12,23]$. One would suspect that the introduction of biologics leading to better disease control would decrease total joint replacement however results have varied depending on joint involvement (especially in terms of total knee replacement) and across countries [23-26]. Some studies have shown a decrease in the incidence of total knee replacement in recent cohorts, while others have shown a stable or even slightly higher rate [23, 24, 27]. Reasons to explain the stable or higher knee arthroplasty rates among contemporary cohorts includes the presence of osteoarthritis despite remission of RA as well as patients with RA now being able to achieve similar pain and function outcomes, when compared to patients with primary osteoarthritis, thanks in part to their ability to participate in physical therapy due to better disease control [28].

Unfortunately, both degenerative changes and active inflammation can necessitate joint replacement and often it is difficult to determine whether joint damage is the result of subclinical or undetected activity versus osteoarthritis. In a study looking at two United Kingdom inception cohorts (1986-1999, 2002-2012) with early RA and on treatment, one of the main findings was that a high proportion of patients required surgical procedures (29\%) with major surgeries (knees, hips) accounting for 35\% of all procedures and intermediate surgeries (wrists, hands, hindfoot/forefoot) accounting for $24 \%$ [23]. Interestingly, while the 10-year cumulative incidence of major interventions remained stable, there was a significant decline in intermediate surgeries. The study also showed that over time there was a trend away from monotherapy and towards combination disease-modifying antirheumatic drugs (DMARDs) therapy including the addition of biologics. One of the questions postulated by the study was whether the unchanged incidence of major intervention with time could be explained by several factors including the presence of osteoarthritis despite better control of RA [23]. Several studies have also shown that women are more likely to undergo joint replacement than men although the exact reason why is unclear $[24,25,29]$.

\section{B. Pain as sequela of treatment}

DMARDs are the mainstay of treatment and the way clinicians try to halt the progression of RA, however they often take time to work and so for more immediate relief, glucocorticoids (GCs) are used. GCs work by quickly decreasing inflammation and synovitis. Long- term, they can also decrease joint damage but are associated with numerous side effects including infection, diabetes, hypertension, adrenal insufficiency, and osteoporosis $[2,30]$. They can also indirectly contribute to non-inflammatory pain by causing changes in body habitus and mood disturbances [31]. They place patients at higher risk for avascular necrosis, fractures, and steroid myopathy [30]. Middle-aged women with RA are at higher risk for fractures given their increased risk for osteoporosis [32]. Due to their adverse side effects, the use of GCs should be limited to the initiation of therapy and during episodes of disease exacerbations, and should be used sparingly as adjunct therapy while DMARDs take effect [33].

Similarly to GCs, all medications for RA can contribute to non-inflammatory discomfort if their side effects outweigh their benefits. DMARDs, particularly the biologics, can also increase the risk of infections [34]. Non-steroidal anti-inflammatory drugs (NSAIDs) can cause gastrointestinal problems including dyspepsia and bleeding. Medications such as duloxetine, gabapentin, and the tricyclic antidepressants that are used for concurrent generalized pain/fibromyalgia can lead to sedation, weight gain, and sexual dysfunction [35]. Opioids should be avoided as their side effect profile not only includes sedation and GI discomfort but can also lead to dependence and opioid-induced hyperalgesia [12, 36, 37].

\section{Pain due to fibromyalgia}

Fibromyalgia (FM) is one of the most common "rheumatic" disorders after osteoarthritis with a suspected prevalence of 2 to $8 \%$ of the population, where it affects women twice as commonly as men [35]. About 12 to $48 \%$ of RA patients have concurrent FM, which can be seen within the first year of diagnosis [38]. Although the exact etiology of FM is unknown, it is considered to be a centralized pain disorder. Patients with FM often report widespread, chronic pain and have a lower threshold for painful stimuli [35]. As previously mentioned, current composite measures of RA disease activity can be affected by the presence of concomitant FM. In fact, several studies show that not all pain in RA is associated with objective measures of inflammation, and this is true particularly in women, although the exact etiology behind this has not been elucidated $[6,13,14,18]$. Women with RA and FM tend to report higher tender joint counts and worse global health status compared to those without FM [18]. As the current focus of treatment is on reducing inflammatory pain, the immediate reaction is to attribute any discomfort to higher disease activity [6]. A prospective cohort study of patients with RA and FM showed that these patients were treated with more leflunomide and prednisone than RA patients without FM 
[39]. It is especially important to differentiate FM pain from inflammatory pain as it can confound disease activity indices leading to unnecessary changes in DMARDs and delaying appropriate therapy.

\section{Pain due to sleep disorders}

Both FM and RA patients often have issues with sleep and fatigue at higher rates than the general population $[20,35,38]$. RA on its own has been associated with poor sleep quality in about 50 to $70 \%$ of patients, in the form of sleep fragmentation, non-restorative sleep, obstructive sleep apnea (OSA), and restless leg syndrome [40-42]. Current literature suggests a bidirectional relationship between sleep and pain where pain can cause sleep disturbances and lack of sleep can result in worsening perception of musculoskeletal pain [20,43]. Both non-optimal sleep and worsening pain have been associated with a decrease in quality of life [42]. In a self-administered questionnaire study involving patients with RA, sleep fragmentation was the most common sleep abnormality reported. The number one reason cited for the nighttime awakening was the "need to use the washroom" followed by pain experienced at night [40]. In this population, poorly controlled pain directly affected patients' quality of sleep. It would have been interesting to see if the number one reason for nighttime awakening was a result of medication side effects. Medications like steroids and certain anti-depressants can cause insomnia, dry mouth, and other side effects that may contribute to frequent bathroom visits.

While the discomforts associated with RA can cause sleep disturbances, poor sleep has also been shown to increase joint pain independent of anxiety and depression [14, 20]. For example, patients with OSA have greater disease activity as represented by DAS28 and higher levels of c-reactive protein [44]. In an experimental model of partial night sleep deprivation comparing patients with RA and control subjects, patients with RA reported worsening pain and an increase in the number of affected joints after sleep loss. Additionally, they had worsening fatigue, anxiety, and depression, which have also been associated with worsened, non-optimal sleep [20]. Given the close relationship between pain, sleep, and mood, it is important to ensure that these non-inflammatory causes of pain are appropriately addressed in order to help with disease control and improve quality of life.

\section{The psychosocial impact of non-inflammatory pain in women with rheumatoid arthritis}

\section{A. Mood disturbances and anxiety in RA}

Unfortunately, patients with chronic illnesses are at higher risk of developing mood disorders and anxiety [45]. RA, like hypertension and diabetes, appears to elevate this risk with the incidence and prevalence of depression, anxiety, and bipolar disorder, being higher, especially among women [46]. As with sleep, there seems to be a bidirectional association between RA and depression. RA increases the risk of depression and depression can increase the pain associated with RA by increasing pain sensitivity $[47,48]$. Post-traumatic stress disorder (PTSD) has also been shown to increase the number of tender joints and exacerbate the pain felt by patients with RA $[49,50]$. It is important then to recognize the emotional burden that RA places on its patients as it can interfere with function, reduce medical adherence, contribute to maladaptive health behaviors, and create risk for greater disease activity and medical co-morbidities [51].

\section{B. Sexual health}

Sexual dysfunction is a highly prevalent problem in patients with RA [52-54]. It is estimated that more than half of RA patients will experience some degree of sexual dysfunction over the course of their lifetimes [52]. Causes are thought to be multifactorial including age, disease duration, sequelae of disease and psychosocial morbidities such as depression, low self-esteem, and decreased body image [53-56]. Limitations with the hips and knees can make it difficult for women with RA to engage in sexual activities and can have a detrimental effect in their quality of life and relationships $[54,56,57]$. After controlling for disease activity and pain intensity, physical performance has been directly related to sexual activity and satisfaction [54].

In addition, patients with RA, especially those with aggressive disease, often experience changes in their physical appearance and function [58]. For example, women with higher degree of morning stiffness have been shown to be more concerned over their body image and have reported more sexual dissatisfaction [59]. Women experiencing weight gain from GCs also report having a poorer perception of their bodies [56]. This can lead to low sexual desire, fear of pain, and a fear of an inability to engage in a satisfying sexual relationship [52].

\section{Disability}

In many individuals, RA can cause difficulties with daily activities. Nearly $85 \%$ of patients have trouble doing household chores, and often women require more assistance than men [60]. The majority of patients (close to $60 \%$ ) also report reducing or completely giving up a leisure-time activity because of their RA [60]. Loss of leisure-time activities has been associated with more fatigue and pain, as well as less self-efficacy in coping with RA [61]. Patients report that their disease makes them less independent and interferes with their activities like working, participating in hobbies, and having support, 
thereby reducing their quality of life [1, 60, 62]. Disability also causes a loss of income to the individual and to society at large. It is estimated that there is a total annual societal loss of approximately $\$ 40$ billion dollars when taking intangible and indirect costs into account [63].

Like depression and sleep disorders, disability causes psychosocial stress affecting the perception of pain. In the BARFOT study, two cohorts of patients with early RA were followed for 8 years with a focus on functional disability and pain [64]. Despite the second cohort being exposed to more aggressive medical treatment and having lower disease activity, pain and functional limitation of both groups were the same, suggesting once again that other factors, apart from disease activity, affect the way pain is interpreted.

The Health Assessment Questionnaire (HAQ) is typically employed to assess physical function. It is a validated questionnaire focusing on daily activities that include eating, dressing, and hygiene among others. A worsening HAQ score has been seen with longer disease duration and is considered to be a predictor of future disability and mortality $[5,65,66]$. Among women, those who are post-menopausal seem to have increased disability as assessed by HAQ. This difference does not appear to be due to radiographic joint destruction suggesting that the functional decline seen in this population is not primarily due to damage and may be related to changes surrounding menopause [5]. Unfortunately, worsening HAQ scores have also been associated with a decrease in quality of life and negatively impacted relationships [67]. The loss of function and disability experienced by patients with RA can worsen depression and sleep disorders, and contributes to social isolation, and a worsened perception of pain [19].

\section{Treatment}

Early in the course of the disease, there can be minimal pain as well as minimal damage to the bone and cartilage, however as the disease progresses it can lead to significant deformities. This is why the focus of treatment has remained on decreasing inflammatory pain. DMARDs have been the cornerstone of therapy as they not only help to alleviate inflammatory pain but prevent further joint damage while improving physical function [16]. DMARDs, as listed in Table 1, are divided into conventional and targeted synthetics, and biologic agents. Older medications, like methotrexate, hydroxychloroquine, leflunomide, azathioprine, cyclosporine, and sulfasalazine are conventional synthetic DMARDs [16]. The targeted synthetic DMARDs are new agents and include tofacitinib and baricitinib, and are known to work by interfering with cell signaling. Biologic agents include the injectables and the infusions such as the TNF-inhibitors (e.g. etanercept, adalimumab,
Table 1 Currently Approved Disease-Modifying Antirheumatic Drugs

\begin{tabular}{|c|c|}
\hline \multicolumn{2}{|l|}{ 1. Synthetic DMARDs } \\
\hline $\begin{array}{l}\text { Conventional } \\
\text { Synthetic DMARDs }\end{array}$ & $\begin{array}{l}\text { Methotrexate, Sulfasalazine, Leflunomide, } \\
\text { Hydroxychloroquine }\end{array}$ \\
\hline $\begin{array}{l}\text { Targeted Synthetic } \\
\text { DMARDs }\end{array}$ & Tofacitinib, Baricitinib \\
\hline \multicolumn{2}{|l|}{ 2. Biologic DMARDs } \\
\hline TNF-inhibitors & $\begin{array}{l}\text { Etanercept, Adalimumab, Infliximab, } \\
\text { Golimumab, Certolizumab }\end{array}$ \\
\hline Anti-B-cell & Rituximab \\
\hline Anti-T-cell & Abatacept \\
\hline Anti-IL-6 receptor & Tocilizumab, Sarilumab \\
\hline
\end{tabular}

infliximab), rituximab, abatacept, the interleukin-6 receptor antagonists tocilizumab and sarilumab, and the interleukin-1 receptor antagonist anakinra.

Opioids and NSAIDs are not sufficient in stopping disease progression despite the fact that they can help control pain and as such are not stand-alone therapies for RA. Similarly, steroids, while they can quickly decrease inflammatory pain, should only be used as an adjunct to DMARD therapy. Both the American College of Rheumatology and the European Union League Against Rheumatism recommend a "treat to target" approach, with a goal of decreasing $50 \%$ of RA activity by 3 months and reaching remission by 6 months of diagnosis. If these targets are not met, a different therapy should be considered [68]. It is this goal of decreasing disease activity that can drive clinicians to switch medications or step up therapy if pain persists; and why it is so essential that the correct type of pain is identified.

Treatment of inflammatory pain remains the focus of most clinicians, yet given the different pain generators in RA and their relationship to one another, it is essential to recognize and embrace the modalities used to treat non-inflammatory pain. Physical and occupational therapy are already widely used and can help decrease both inflammatory and non-inflammatory pain through muscle strengthening and stabilization of the joints.

Patients with RA can often experience "rheumatoid cachexia" which occurs as a rapid loss of muscle mass due to protein degradation from excess of proinflammatory cytokines [69]. Body weight remains stable but the loss in muscle mass contributes to weakness, fatigue, and decreased movement. These changes place the patient at risk for functional disability and worsen inflammatory pain by having patients change their natural posture and the way they move in order to compensate for the painful joint. High intensity resistance exercise can help reverse cachexia by increasing muscle mass and strength while helping to stabilize joints and preventing 
contractures $[69,70]$. Physical activity may also promote health of the joint by increasing joint lubrication during exercise [69].

Physical and occupational therapy can help with noninflammatory pain by decreasing the risk of disability and increasing independence [71]. Physical activity in general, even unsupervised, has been associated with a positive influence in quality of life [72]. Occupational therapy can help patients improve their ability to perform a functional task, allowing them to achieve independence and autonomy. Preservation of autonomy is essential in patients with RA as it decreases anxiety and preserves psychological well-being [22]. Other modalities shown to improve quality of life and promote functional benefits include electrotherapy and mud therapy. Aquatic therapy may have positive effects in patients with RA who are unable to engage in traditional physical therapy [73-75].

Like other forms of chronic pain, the pain in RA is multifactorial and treatment options can vary. Cognitive behavioral therapy (CBT) has been studied in patients with chronic pain conditions, chronic low back pain, osteoarthritis, fibromyalgia, as well as in different psychiatric disorders including depression, PTSD, and generalized anxiety disorder [76]. It is also first-line treatment for chronic insomnia [77]. CBT focuses on identifying and changing behaviors and thoughts that are maladaptive while helping patients develop coping strategies. It may help to ameliorate pain and disability by changing attitudes towards the illness. In a study looking at patients with recent onset $(<2$ years $)$ of seropositive RA, those that receive CBT had a reduction in depressive symptoms and c-reactive protein as well as an improvement in joint involvement compared to those who did not receive CBT [78]. Other studies have shown that CBT can reduce disability, depression/anxiety, and painrelated fear but do not decrease pain intensity [79]. Interestingly, CBT may also change brain function and neuronal connection as magnetic resonance imaging done after treatment with CBT show increase activation in the prefrontal cortex, an area of the brain that is involved in regulating emotions to painful stimuli [76].

In recent years, complementary/alternative medicine (CAM) such as acupuncture has been used in the treatment of chronic conditions like RA [80]. Acupuncture may provide short term analgesia by creating up-regulation of endogenous opioids and serotonin [81]. One study showed that it can help improve quality of life by decreasing the number of tender joints although this effect is short-lived [80].

Fibromyalgia should be addressed if present. Its treatment includes both pharmacologic and non-pharmacological approaches [82]. The non-pharmacological treatments include CBT, aerobic exercises, tai-chi, yoga, hydrotherapy and acupuncture [82, 83]. Most recently, tai-chi showed similar or greater improvement in symptoms than aerobic exercises which is the current most commonly prescribed non-pharmacological treatment modality for FM [84]. Combining various modalities has also been shown to be effective in decreasing pain, fatigue, and depression, and can also improve quality of life although effects are not long-lasting [83].

Pharmaceutical therapies for FM include amitriptyline (a tricyclic antidepressant) and anticonvulsants like gabapentin and pregabalin $[85,86]$. Treatment options also include the serotonin-noradrenaline reuptake inhibitors (SNRIs): duloxetine and milnacipran. In a subgroup analysis of patients with RA with well-controlled inflammation and widespread pain, milnacipran was found to decrease pain after 6 weeks of medication use [87]. As fibromyalgia and depression can often co-exist, duloxetine (which has a stronger effect on serotonin than does milnacipran) is an ideal choice for these patients $[85,86]$. In individuals with RA and stand-alone anxiety and/or depression, the clinician may also wish to consider using selective serotonin reuptake inhibitors (SSRIs) like fluoxetine and encourage physical activity. Other pharmaceutical modalities for fibromyalgia include cyclobenzaprine $[85,86]$. The use of opioids is discouraged because of the lack of efficacy in FM patients in addition to the high risk of side effects and addiction [85].

Patients with RA who are experiencing sexual dysfunction due to difficulties with sexual intercourse should be encouraged to have a open discussion with their partners as communication can help everyone feel more comfortable. Patients can also find different positions and/or explore alternative ways of expressing sexuality. Patients can also try analgesics, heat, and muscle relaxants before engaging in sexual activity. Vaginal lubrication and estrogen cream can be used for dyspareunia. Those experiencing decreased libido should be ruled out for medication side effects and depression. Anti-depressants, medications such as sildenafil, and sex therapy can be pursued as needed [52, 88].

Sleep disorders should also be addressed as they can negatively impact well-being and function [42]. At times, patients are not even aware that they have poor sleep. In a study looking at thirty female patients with RA, fourteen met the criteria for diagnosis of OSA despite six of them reporting not having any sleep problems [44]. Patients with RA and fatigue and/or poor sleep, benefit from an evaluation for restless leg syndrome and OSA. After diagnosis, continuous positive airway pressure or pharmacological therapy for restless leg syndrome can be pursued. Other types of sleep issues include insomnia and non-restorative sleep. Medication side effects should be ruled out and sleep hygiene should be encouraged. CBT can be used if insomnia persists, and in fact is first 
line therapy [89]. Studies have shown that 70 to $80 \%$ of patients benefit from CBT and approximately $40 \%$ achieve remission from insomnia [90]. While it is common to use antidepressants to help improve sleep, there are not enough quality studies to determine whether the effect is significant although they may work better if poor sleep is a result of depression [91]. Hypnotic drugs, like benzodiazepines, should be avoided as they can induce tolerance and dependence and in the elderly population can cause falls $[91,92]$.

\section{Take away points and conclusion}

RA is described as a chronic, systemic, inflammatory disease that affects mainly the joints of the hands and the feet. Typically, active disease presents with pain and when left untreated can cause joint deformities and disability. In this context pain is often used as a proxy for active disease. Traditionally, the evaluation of pain in RA has focused on inflammation yet patients with RA also experience non-inflammatory pain such as mechanical pain (like osteoarthritis), neuropathic pain, fibromyalgia, side effects of treatment, as well as the psychosocial sequela from the disease like depression, anxiety, sleep disturbances, sexual dysfunction, and disability $[1,6,12,13]$. Often there is also a reciprocal relationship between disease and the noninflammatory pain generator. Mood and sleep in particular have a bidirectional relationship with active disease [20, 47].

Given the current approach in treating RA, a significant amount of women's pain is not being adequately addressed. Moreover, when asked to choose an area of health that they wished would improve, close to $70 \%$ of women choose pain even above walking, mobility, and hand and finger function [93]. This suggests that more attention needs to be paid to patients' preferences. Clinicians may be happy with the lack of synovitis while patients suffer due to depression or fibromyalgia. When left untreated, non-inflammatory pain, like joint deformities can have tremendous impact on patients' quality of life and mobility [60,61]. Ultimately, in order to recognize the various ways in which RA can cause pain, providers need to broaden their sense of what RA is and how patients experience the disease. Only by reimagining RA, can non-inflammatory causes of pain be recognized and be treated accordingly.

\footnotetext{
Abbreviations

ACPA: Anti-citrullinated peptide antibody; CAM: Complementary/alternative medicine; CBT: Cognitive behavioral therapy; CDAl: Clinical disease activity index; DMARDs: Disease-modifying antirheumatic drugs; FM: Fibromyalgia; GCs: Glucocorticoids; HAQ: Health Assessment Questionnaire; IL-1: Interleukin-1; NSAIDs: Non-steroidal anti-inflammatory drugs; OSA: Obstructive sleep apnea; PTSD: Post traumatic stress disorder RA: Rheumatoid arthritis; RF: Rheumatoid factor; SDAl: Simplified disease activity index; SE: Shared epitope; SNRIs: Serotonin-noradrenaline reuptake inhibitors; SSRIs: Selective serotonin reuptake inhibitors; TNF-alpha: Tumor necrosis factor-alpha
}

Acknowledgements

Not applicable

Author's contributions

All authors read and approved the final manuscript.

Author's information

Not applicable

Funding

Not applicable

Availability of data and materials

Not applicable

Ethics approval and consent to participate

Not applicable

Consent for publication

Not applicable

\section{Competing interests}

The authors declare that they have no competing interests.

\section{Author details}

'Department of Rheumatology, Albert Einstein College of Medicine, 1300 Morris Park Ave, Forchh 701N, Bronx, NY 10461, USA. ${ }^{2}$ Department of Medicine, Jacobi Medical Center, 1400 Pelham Pkwy S, Bronx, NY 10461, USA.

Received: 21 December 2018 Accepted: 1 August 2019

Published online: 09 August 2019

\section{References}

1. Minnock P, FitzGerald O, Bresnihan B. Women with established rheumatoid arthritis perceive pain as the predominant impairment of health status. Rheumatology (Oxford). 2003:42(8):995-1000.

2. Scott DL, Wolfe F, Huizinga TW. Rheumatoid arthritis. Lancet. 2010; 376(9746):1094-108.

3. Jawaheer D, Lum RF, Gregersen PK, Criswell LA. Influence of male sex on disease phenotype in familial rheumatoid arthritis. Arthritis Rheum. 2006; 54(10):3087-94

4. Alpízar-Rodríguez D, Finckh AJSil. Environmental factors and hormones in the development of rheumatoid arthritis 2017;39(4):461-8.

5. Alpizar-Rodriguez D, Forger F, Courvoisier DS, Gabay C, Finckh A. Role of reproductive and menopausal factors in functional and structural progression of rheumatoid arthritis: results from the SCQM cohort. Rheumatology (Oxford). 2018.

6. Sokka T, Toloza S, Cutolo M, Kautiainen H, Makinen H, Gogus F, et al. Women, men, and rheumatoid arthritis: analyses of disease activity, disease characteristics, and treatments in the QUEST-RA Study. 2009;11(1):R7.

7. Silman A, Kay A, Brennan P. Timing of pregnancy in relation to the onset of rheumatoid arthritis. Arthritis Rheum. 1992:35(2):152-5.

8. Karlson EW, Mandl LA, Hankinson SE, Grodstein F. Do breast-feeding and other reproductive factors influence future risk of rheumatoid arthritis? Results from the Nurses' health study. Arthritis Rheum. 2004;50(11):3458-67.

9. Bengtsson C, Malspeis S, Orellana C, Sparks JA, Costenbader KH, Karlson EW. Association between menopausal factors and the risk of seronegative and seropositive rheumatoid arthritis: results from the Nurses' health studies. Arthritis Care Res. 2017;69(11):1676-84.

10. Jeong HS, Hong SJ, Choi SJ, Kim JH, Song GG, Jung JH. Effects of oral contraceptives on rheumatoid arthritis in Korean menopausal women: a nationwide cross-sectional study. Maturitas. 2018:112:24-8.

11. Hall GM, Daniels M, Huskisson EC, Spector TD. A randomised controlled trial of the effect of hormone replacement therapy on disease activity in postmenopausal rheumatoid arthritis. Ann Rheum Dis. 1994:53(2):112-6.

12. Sarzi-Puttini P, Salaffi F, Di Franco M, Bazzichi L, Cassisi G, Casale R, et al. Pain in rheumatoid arthritis: a critical review. Reumatismo. 2014;66(1):18-27.

13. Bilberg A, Bremell T, Bjersing J, Mannerkorpi K. High prevalence of widespread pain in women with early rheumatoid arthritis. Scand $J$ Rheumatol. 2018:1-8. 
14. Boyden SD, Hossain IN, Wohlfahrt A, YCJCRR L. Non-inflammatory Causes of Pain in Patients with Rheumatoid Arthritis. 2016;18(6):30.

15. Fu J, Nogueira SV, Drongelen W, Coit P, Ling S, Rosloniec EF, et al. Shared epitope-aryl hydrocarbon receptor crosstalk underlies the mechanism of gene-environment interaction in autoimmune arthritis. Proc Natl Acad Sci U S A. 2018;115(18):4755-60.

16. Aletaha D, Smolen JS. Diagnosis and management of rheumatoid arthritis: a review. JAMA. 2018;320(13):1360-72.

17. Andonopoulos AP, Drosos AA, Skopouli FN, Acritidis NC, Moutsopoulos HM. Secondary Sjogren's syndrome in rheumatoid arthritis. J Rheumatol. 1987; 14(6):1098-103.

18. Salaffi F, Di Carlo M, Carotti M, Sarzi-Puttini PJRI. The subjective components of the Disease Activity Score 28-joints (DAS28) in rheumatoid arthritis patients and coexisting fibromyalgia. 2018;38(10):1911-8.

19. Grabovac I, Haider S, Berner C, Lamprecht T, Fenzl KH, Erlacher L, et al. Sleep Quality in Patients with Rheumatoid Arthritis and Associations with Pain, Disability, Disease Duration, and Activity. J Clin Med. 2018;7(10):336.

20. Irwin MR, Olmstead R, Carrillo C, Sadeghi N, Fitzgerald JD, Ranganath VK, et al. Sleep loss exacerbates fatigue, depression, and pain in rheumatoid arthritis. Sleep. 2012;35(4):537-43.

21. Koop SM, ten Klooster PM, Vonkeman HE, Steunebrink LM, van de Laar MA. Neuropathic-like pain features and cross-sectional associations in rheumatoid arthritis. Arthritis Res Ther. 2015;17:237.

22. Ryan S, McGuire B. Psychological predictors of pain severity, pain interference, depression, and anxiety in rheumatoid arthritis patients with chronic pain. Br J Health Psychol. 2016;21(2):336-50.

23. Nikiphorou E, Carpenter L, Morris S, Macgregor AJ, Dixey J, Kiely P, et al. Hand and foot surgery rates in rheumatoid arthritis have declined from 1986 to 2011, but large-joint replacement rates remain unchanged: results from two UK inception cohorts. Arthritis Rheumatol. 2014;66(5):1081-9.

24. Shourt CA. Orthopedic surgery among patients with rheumatoid arthritis 1980-2007: a population-based study focused on surgery rates, sex, and mortality. J Rheumatol. 2012;39(3):481-5.

25. Massardo L, Gabriel SE, Crowson CS, O'Fallon WM, Matteson EL. A population based assessment of the use of orthopedic surgery in patients with rheumatoid arthritis. J Rheumatol. 2002;29(1):52-6.

26. Cordtz RL, Hawley S, Prieto-Alhambra D, Hojgaard P, Zobbe K, Overgaard S, et al. Incidence of hip and knee replacement in patients with rheumatoid arthritis following the introduction of biological DMARDs: an interrupted time-series analysis using nationwide Danish healthcare registers. Ann Rheum Dis. 2018;77(5):684-9.

27. Mertelsmann-Voss C, Lyman S, Pan TJ, Goodman SM, Figgie MP, Mandl LA US trends in rates of arthroplasty for inflammatory arthritis including rheumatoid arthritis, juvenile idiopathic arthritis, and spondyloarthritis. Arthritis Rheumatol. 2014;66(6):1432-9.

28. Goodman SM, Johnson B, Zhang M, Huang W-T, Zhu R, Figgie M, et al. Patients with rheumatoid arthritis have similar excellent outcomes after Total knee replacement compared with patients with osteoarthritis. J Rheumatol. 2016:43(1):46-53.

29. Stundner O, Danninger T, Chiu Y-L, Sun X, Goodman SM, Russell LA, et al. Rheumatoid arthritis vs osteoarthritis in patients receiving Total knee arthroplasty: perioperative outcomes. J Arthroplast. 2014;29(2):308-13.

30. Krasselt $M$, Baerwald $C$. The current relevance and use of prednisone in rheumatoid arthritis. Expert Rev Clin Immunol. 2014;10(5):557-71.

31. Liu D, Ahmet A, Ward L, Krishnamoorthy P, Mandelcorn ED, Leigh R, et al. A practical guide to the monitoring and management of the complications of systemic corticosteroid therapy. Allergy Asthma Clin Immunol. 2013;9(1):30.

32. Hoes JN, Bultink IE, Lems WF. Management of osteoporosis in rheumatoid arthritis patients. Expert Opin Pharmacother. 2015;16(4):559-71.

33. Smolen JS, Landewe R, Bijlsma J, Burmester G, Chatzidionysiou K, Dougados $M$, et al. EULAR recommendations for the management of rheumatoid arthritis with synthetic and biological disease-modifying antirheumatic drugs: 2016 update. Ann Rheum Dis. 2017;76(6):960-77.

34. Singh JA, Cameron C, Noorbaloochi S, Cullis T, Tucker M, Christensen R, et al. Risk of serious infection in biological treatment of patients with rheumatoid arthritis: a systematic review and meta-analysis. Lancet (London, England). 2015;386(9990):258-65.

35. Clauw DJ. Fibromyalgia: a clinical review. JAMA. 2014;311(15):1547-55.

36. Whittle SL, Richards BL, Husni E, Buchbinder R. Opioid therapy for treating rheumatoid arthritis pain. Cochrane Database Syst Rev. 2011;11.
37. Crofford LJ. Adverse effects of chronic opioid therapy for chronic musculoskeletal pain. Nat Rev Rheumatol. 2010;6(4):191-7.

38. Gist AC, Guymer EK, Eades LE, Leech M, Littlejohn GO. Fibromyalgia remains a significant burden in rheumatoid arthritis patients in Australia. Int J Rheum Dis. 2018;21(3):639-46.

39. RMdS C, Brenol C, Ranzolin A, Bernardes A, Dalosto AP, Ferrari G, et al. Rheumatoid arthritis seems to have DMARD treatment decision influenced by fibromyalgia. Revista Brasileira de Reumatologia (English Edition). 2017;57(5):403-11.

40. Taylor-Gjevre RM, Gjevre JA, Nair B, Skomro R, Lim HJ. Components of sleep quality and sleep fragmentation in rheumatoid arthritis and osteoarthritis. Musculoskeletal care. 2011;9(3):152-9.

41. Abbasi M, Yazdi Z, Rezaie N. Sleep disturbances in patients with rheumatoid arthritis. Niger J Med. 2013;22(3):181-6.

42. Purabdollah M, Lakdizaji S, Rahmani A, Hajalilu M, Ansarin K. Relationship between sleep disorders, pain and quality of life in patients with rheumatoid arthritis. J Caring Sci. 2015;4(3):233-41.

43. Moldofsky H. Rheumatic manifestations of sleep disorders. Curr Opin Rheumatol. 2010;22(1):59-63.

44. Fouda N, Dayem AA. Obstructive sleep apnea in patients with rheumatoid arthritis: correlation with disease activity and pulmonary function tests. Egypt Rheumatol. 2014;36(4):165-71.

45. Wells KB, Golding JM, Burnam MA. Psychiatric disorder in a sample of the general population with and without chronic medical conditions. Am J Psychiatry. 1988;145(8):976-81.

46. Marrie RA, Hitchon CA, Walld R, Patten SB, Bolton JM, Sareen J, et al. Increased burden of psychiatric disorders in rheumatoid arthritis. Arthritis Care Res. 2018;70(7):970-8

47. Lu MC, Guo HR, Lin MC, Livneh H, Lai NS, Tsai TY. Bidirectional associations between rheumatoid arthritis and depression: a nationwide longitudinal study. Sci Rep. 2016;6:20647.

48. Edwards RR, Cahalan C, Mensing G, Smith M, Haythornthwaite JA. Pain, catastrophizing, and depression in the rheumatic diseases. Nat Rev Rheumatol. 2011;7(4):216-24.

49. Boscarino JA, Forsberg CW, Goldberg J. A twin study of the association between PTSD symptoms and rheumatoid arthritis. Psychosom Med. 2010; 72(5):481-6.

50. Mikuls TR, Padala PR, Sayles HR, Yu F, Michaud K, Caplan L, et al. Prospective study of posttraumatic stress disorder and disease activity outcomes in US veterans with rheumatoid arthritis. Arthritis Care Res. 2013;65(2):227-34.

51. van't Land H, Verdurmen J, Ten Have M, van Dorsselaer S, Beekman A, de Graaf $\mathrm{R}$. The association between arthritis and psychiatric disorders; results from a longitudinal population-based study. J Psychosom Res. 2010;68(2):187-93.

52. Abdel-Nasser AM, Ali El. Determinants of sexual disability and dissatisfaction in female patients with rheumatoid arthritis. Clin Rheumatol. 2006;25(6):822-30.

53. van Berlo WT, van de Wiel HB, Taal E, Rasker JJ, Weijmar Schultz WC, van Rijswijk MH. Sexual functioning of people with rheumatoid arthritis: a multicenter study. Clin Rheumatol. 2007:26(1):30-8.

54. Dorner TE, Berner C, Haider S, Grabovac I, Lamprecht T, Fenzl KH, et al. Sexual health in patients with rheumatoid arthritis and the association between physical fitness and sexual function: a cross-sectional study. Rheumatol Int. 2018;38(6):1103-14.

55. Zhao S, Li E, Wang J, Luo L, Luo J, Zhao Z. Rheumatoid Arthritis and Risk of Sexual Dysfunction: A Systematic Review and Metaanalysis. The Journal of rheumatology. 2018

56. Josefsson KA, Gard G. Women's experiences of sexual health when living with rheumatoid arthritis--an explorative qualitative study. BMC Musculoskelet Disord. 2010;11:240.

57. Yoshino S, Uchida S. Sexual problems of women with rheumatoid arthritis. Arch Phys Med Rehabil. 1981;62(3):122-3.

58. Alleva JM, Diedrichs PC, Halliwell E, Peters ML, Dures E, Stuijfzand BG, et al. More than my RA: a randomized trial investigating body image improvement among women with rheumatoid arthritis using a functionality-focused intervention program. J Consult Clin Psychol. 2018:86(8):666-76.

59. Gutweniger S, Kopp M, Mur E, Gunther V. Body image of women with rheumatoid arthritis. Clin Exp Rheumatol. 1999;17(4):413-7.

60. Leino M, Tuominen S, Pirila L, Tuominen R. Effects of rheumatoid arthritis on household chores and leisure-time activities. Rheumatol Int. 2015;35(11):1881-8. 
61. Reinseth L, Uhlig T, Kjeken I, Koksvik HS, Skomsvoll JF, Espnes GA. Performance in leisure-time physical activities and self-efficacy in females with rheumatoid arthritis. Scand J Occup Ther. 2011;18(3):210-8.

62. Verstappen SM. Rheumatoid arthritis and work: the impact of rheumatoid arthritis on absenteeism and presenteeism. Best Pract Res Clin Rheumatol. 2015;29(3):495-511.

63. Birnbaum H, Pike C, Kaufman R, Marynchenko M, Kidolezi Y, Cifaldi M. Societal cost of rheumatoid arthritis patients in the US. Curr Med Res Opin 2010;26(1):77-90.

64. Andersson MLE, Forslind K, Hafstrom I. Patients with early rheumatoid arthritis in the 2000s have equal disability and pain despite less disease activity compared with the 1990s: data from the BARFOT study over 8 years. J Rheumatol. 2017;44(6):723-31.

65. Toussirot E. Predictive factors for disability as evaluated by the health assessment questionnaire in rheumatoid arthritis: a literature review. Inflamm Allergy Drug Targets. 2010;9(1):51-9.

66. Sokka T. Work disability in early rheumatoid arthritis. Clin Exp Rheumatol. 2003;21(5 Suppl 31):S71-4.

67. Mclnnes IB, Combe B, Burmester $\mathrm{G}$. Understanding the patient perspective results of the rheumatoid arthritis: insights, strategies \& expectations (RAISE) patient needs survey. Clin Exp Rheumatol. 2013;31(3):350-7.

68. Smolen JS, Breedveld FC, Burmester GR, Bykerk V, Dougados M, Emery $P$, et al. Treating rheumatoid arthritis to target: 2014 update of the recommendations of an international task force. Ann Rheum Dis. 2016;75(1):3-15.

69. Cooney JK, Law R-J, Matschke V, Lemmey AB, Moore JP, Ahmad Y, et al. Benefits of exercise in rheumatoid arthritis. J Aging Res. 2011;2011:681640,

70. Kavuncu V, Evcik D. Physiotherapy in rheumatoid arthritis. MedGenMed. 2004;6(2):3.

71. Iversen MD, Brawerman M, Iversen CN. Recommendations and the state of the evidence for physical activity interventions for adults with rheumatoid arthritis: 2007 to present. Int J Clin Rheumtol. 2012;7(5):489-503.

72. Blake H. Physical activity and exercise in the treatment of depression. Front Psychiatry. 2012;3:106.

73. Bartels EM, Lund H, Danneskiold-Samsoe B. Pool exercise therapy of rheumatoid arthritis. Ugeskr Laeger. 2001;163(40):5507-13.

74. Deyle GD, Henderson NE, Matekel RL, Ryder MG, Garber MB, Allison SC. Effectiveness of manual physical therapy and exercise in osteoarthritis of the knee. A randomized, controlled trial. Ann Intern Med. 2000;132(3):173-81.

75. Mustur D, Vujasinovic-Stupar N. The impact of physical therapy on the quality of life of patients with rheumatoid and psoriatic arthritis. Med Pregl. 2007;60(5-6):241-6.

76. Urits I, Hubble A, Peterson E, Orhurhu V, Ernst CA, Kaye AD, et al. An update on cognitive therapy for the Management of Chronic Pain: a comprehensive review. Curr Pain Headache Rep. 2019;23(8):57.

77. Trauer JM, Qian MY, Doyle JS, Rajaratnam SM, Cunnington D. Cognitive behavioral therapy for chronic insomnia: a systematic review and metaanalysis. Ann Intern Med. 2015;163(3):191-204

78. Sharpe L, Sensky T, Timberlake N, Ryan B, Brewin CR, Allard S. A blind, randomized, controlled trial of cognitive-behavioural intervention for patients with recent onset rheumatoid arthritis: preventing psychological and physical morbidity. Pain. 2001;89(2-3):275-83.

79. Vibe Fersum K, Smith A, Kvale A, Skouen JS, O'Sullivan P. Cognitive functional therapy in patients with non-specific chronic low back pain-a randomized controlled trial 3-year follow-up. Eur J Pain. 2019.

80. Tam LS, Leung PC, Li TK, Zhang L, Li EK. Acupuncture in the treatment of rheumatoid arthritis: a double-blind controlled pilot study. BMC Complement Altern Med. 2007;7:35.

81. Amezaga Urruela M, Suarez-Almazor ME. Acupuncture in the treatment of rheumatic diseases. Curr Rheumatol Rep. 2012;14(6):589-97.

82. Theoharides TC, Tsilioni I, Arbetman L, Panagiotidou S, Stewart JM, Gleason RM, et al. Fibromyalgia syndrome in need of effective treatments. J Pharmacol Exp Ther. 2015;355(2):255-63

83. Hauser W, Bernardy K, Arnold B, Offenbacher M, Schiltenwolf M. Efficacy of multicomponent treatment in fibromyalgia syndrome: a meta-analysis of randomized controlled clinical trials. Arthritis Rheum. 2009;61(2):216-24.

84. Wang C, Schmid CH, Fielding RA, Harvey WF, Reid KF, Price LL, et al. Effect of tai chi versus aerobic exercise for fibromyalgia: comparative effectiveness randomized controlled trial. BMJ. 2018;360:k851.
85. Macfarlane GJ, Kronisch C, Dean LE, Atzeni F, Hauser W, Fluss E, et al. EULAR revised recommendations for the management of fibromyalgia. Ann Rheum Dis. 2017;76(2):318-28

86. Kia S, Choy E. Update on Treatment Guideline in Fibromyalgia Syndrome with Focus on Pharmacology. Biomedicines. 2017;5(2):20.

87. Lee YC, Massarotti E, Edwards RR, Lu B, Liu C, Lo Y, et al. Effect of Milnacipran on pain in patients with rheumatoid arthritis with widespread pain: a randomized blinded crossover trial. J Rheumatol. 2016;43(1):38-45.

88. Tristano AG. Impact of rheumatoid arthritis on sexual function. World J Orthop. 2014;5(2):107-11.

89. Jungquist CR, O'Brien C, Matteson-Rusby S, Smith MT, Pigeon WR, Xia Y, et al. The efficacy of cognitive-behavioral therapy for insomnia in patients with chronic pain. Sleep Med. 2010;11(3):302-9.

90. Arnedt JT, Cuddihy L, Swanson LM, Pickett S, Aikens J, Chervin RD. Randomized controlled trial of telephone-delivered cognitive behavioral therapy for chronic insomnia. Sleep. 2013;36(3):353-62.

91. Everitt H, Baldwin DS, Stuart B, Lipinska G, Mayers A, Malizia AL, et al. Antidepressants for insomnia in adults. Cochrane Database Syst Rev. 2018;5:Cd010753.

92. Tannenbaum C, Diaby V, Singh D, Perreault S, Luc M, Vasiliadis HM. Sedative-hypnotic medicines and falls in community-dwelling older adults: a cost-effectiveness (decision-tree) analysis from a US Medicare perspective. Drugs Aging. 2015;32(4):305-14.

93. Heiberg T, Kvien TK. Preferences for improved health examined in 1,024 patients with rheumatoid arthritis: pain has highest priority. Arthritis Rheum. 2002:47(4):391-7.

\section{Publisher's Note}

Springer Nature remains neutral with regard to jurisdictional claims in published maps and institutional affiliations.

Ready to submit your research? Choose BMC and benefit from:

- fast, convenient online submission

- thorough peer review by experienced researchers in your field

- rapid publication on acceptance

- support for research data, including large and complex data types

- gold Open Access which fosters wider collaboration and increased citations

- maximum visibility for your research: over $100 \mathrm{M}$ website views per year

At $\mathrm{BMC}$, research is always in progress.

Learn more biomedcentral.com/submissions 